\title{
GUACIRA LOPES LOURO FALA AOS CADERNOS DE GÊNERO E TECNOLOGIA
}

É com muita satisfação que compartilhamos com nossos leitores esta conversa que tivemos com a professora Guacira Lopes Louro em uma tarde chuvosa e fria de sábado em Curitiba. A entrevista foi realizada entre uma decolagem e outra do aeroporto Afonso Pena enquanto aguardava o horário para o seu retorno a Porto Alegre. Era o dia 18 de outubro de 2008 e ela havia ministrado, no período da manhã, a palestra Gênero e Sexualidade nas práticas educativas contemporâneas no encerramento do curso Construindo a igualdade na escola: repensando conceitos e preconceitos de gênero e nos brindou com esta entrevista.

Dona de um extenso currículo, com inúmeras publicações no Brasil e no exterior, Guacira exibe uma simpatia e generosidade invejáveis. Nas páginas que segue, Ela compartilha conosco a sua trajetória pessoal e profissional, algumas de suas realizações, bem como sua forma de pensar assuntos relacionados a temática de gênero e diversidade sexual.

Esperamos que seja uma leitura agradável e enriquecedora.

\section{CGT: Fale sobre sua trajetória pessoal e acadêmica até chegar aos estudos feministas e de gênero.}

Guacira: Cursei a Escola Normal em Porto Alegre e depois estudei História. A seguir, fui trabalhar no Colégio de Aplicação da Universidade Federal do Rio Grande do Sul (UFRGS). Após, prestei concurso para esta universidade na área da História da Educação. Talvez isso explique um pouco minha caminhada até entrar no campo de Estudos Feministas e de Gênero. O Instituto de Educação era uma instituição marcadamente feminina, apesar de não ter uma proibição para o ingresso de rapazes. Essa proibição havia no Ginásio, mas não havia no Primário e no Normal. Apesar disso é possível dizer que esta era uma escola para formação de mulheres. Mais tarde, já licenciada em História, fui dar aulas no curso de Pedagogia, como professora de "História da Educação" e entre os/as estudantes (fundamentalmente mulheres), a pergunta mais freqüente era: "Onde estão as mulheres na História?" As muIheres estavam escondidas e isso me levou a ter interesse de ver como foi o processo de educação das meninas e das mulheres - algo que era colocado ou em nota de rodapé ou apresentado excepcionalmente, em qualquer setor e mesmo lá na UFRGS.

No início dos anos 1980 fui cursar Doutorado na Universidade Estadual de Campinas (UNICAMP), com uma bolsa que se chamava PICD. Para mim, a UNICAMP tinha naquele momento um trabalho mais revolucionário que o da UFRGS, já que, dentre outras coisas, trabalhava mais com uma orientação marxista. Eu precisava elaborar um anteprojeto para começar o Doutorado; 
achei que ele poderia se enraizar justamente na minha própria história. Com a pretensão ambiciosa que usualmente se tem ao iniciar um projeto de tese, pensei em de desenvolver estudos sobre a história da mulher no Rio Grande do Sul. Fui fazendo recortes, é claro, até chegar a uma dimensão efetivamente razoável e viável para dar conta no prazo do doutorado, então, acabei estudando a formação das mulheres no Instituto de Educação em Porto Alegre. Na verdade, minha tese de doutorado foi uma análise da formação das mulheres em uma escola marcadamente feminina, tal como tinha sido a escola onde fiz a minha formação. Acho que a tese acabou sendo também uma espécie de um "ajuste de contas" com a minha própria vida. Além de farta documentação escrita, usei depoimentos de alunas e professoras. Eu mesma era uma ex-aluna, que tinha entrado com 5 (cinco) anos de idade e saído com 20 (vinte). A tese, que se intitula "Prendas e Antiprendas", foi defendida em 1986 e acabou se constituindo na minha entrada no campo que se chamava, então, "Estudos de Mulher". Depois disso é que entrei em contato com o conceito de gênero.

\section{CGT: Você já era professora?}

Guacira: Eu já era professora na UFRGS; tinha feito concurso para professora auxiliar e adjunta; trabalhava com História da Educação. Ao voltar do Doutorado e retomar meu trabalho de professora na graduação, comecei a introduzir questões sobre a educação da mulher. Fui convidada para trabalhar na pós-graduação que era o caminho normal de quem regressava com Doutorado. Como a estrutura da pós-graduação já era (e continua sendo) muito flexível, era possível oferecer seminários com qualquer temática. Não havia nada que fosse obrigatório. Ministrei um primeiro seminário sobre "História da Educação da Mulher"; a seguir, "Educação e Mulher"; pouco depois, "Educação e Gênero" e, desde então, tenho trabalhado nessa área. Portanto, efetivamente, foi o Doutorado que me abriu de vez essa porta e que me fez abordar essa questão. Tive uma boa acolhida do pessoal do Pós graduação da UFRGS o que facilitou a continuidade desta trajetória.

\section{CGT: Como foi a inserção do tema de Estudos sobre Mulher e depois Estudos de Gênero na Faculdade de Educação na UFRGS?}

Guacira: Não sei se posso falar na UFRGS em geral, mas posso falar mais na Faculdade de Educação. Ali não tive problemas em introduzir estas temáticas, acho que, em parte, porque eu era uma professora bastante integrada nas atividades da graduação e do Pós e também porque já havia um certo "clima" que ajudava. Na UFRGS existe, desde os anos 1980, no IFCH (Instituto de Filosofia e Ciências Humanas), um núcleo interdisplinar de estudos sobre a mulher.

\section{CGT: Mas já existia algo direcionado a tais estudos, ou foi você quem come- çou?}

Guacira: Na Faculdade de Educação, acho que posso dizer que fui eu que 
comecei. O pessoal da Faced respeitava meu trabalho e quase todos acoIheram bem essas questões. Não vou dizer que elas foram imediatamente aceitas por todo mundo. As questões circulavam em uma espécie de "departamento" separado: alguns diziam: "ah, a Guacira, está lá com aqueles/ as seus/suas alunos/as trabalhando...". Mas não tive hostilidade; não tenho história dramática para contar de que eu queria fazer alguma coisa e não me deixavam.

Foi curioso perceber como alguns recebiam estes temas. Lembro que em um dos primeiros seminários que ministrei praticamente havia só mulheres e um rapaz. No primeiro dia perguntei a cada um/a: "Por que você está aquie?" Ele respondeu claramente, embora meio tímido: "Eu queria entender as muIheres". Ele era jovem. Então, o seminário para ele parecia algo instrumental, direcionado para se dar bem com as mulheres, o que de fato não era. Lutei muito desde o início para evitar que as aulas se transformassem num bate -papo ou num espaço de conscientização. Não era essa a proposta, embora houvesse uma possibilidade bem forte disso acontecer, ou seja, as pessoas estavam a fim de contar suas experiências, usando expressões como, por exemplo: "eu com a minha sogra" e "eu com a minha mãe, minhas filhas e tal"; enfim, num tom que parecia exigir uma troca de confidências ou de experiências. Para evitar este clima, desde o princípio fiz muito empenho em enfatizar a teorização. Eu dizia: "nós não estamos aqui para resolver, e/ou compartilhar nossa situação feminina; isso pode ser ótimo, mas nós podemos fazer isso em outro espaço; aqui nós podemos até partir dessas experiências, mas nosso objetivo é estudar e teorizar". Com essas atividades é que entrei em contato (e começamos a trabalhar) com o conceito de gênero. O conceito "chegou" através do texto da Joan Scott, que uma colega da UFMG, a Eliane Marta Teixeira Lopes, levou para Porto Alegre numa versão em francês. Eu acabei traduzindo o artigo e ele foi publicado na revista Educação e Realidade ${ }^{50}$.

Há algo que quero contar, que considero muito importante nesta caminhada. É o seguinte fato: quando iniciei o trabalho nesse campo de estudos, aos poucos começaram a aparecer pessoas que queriam fazer pesquisa nessa área. Inicialmente, tive orientandas de Mestrado que queriam estudar "questões da mulher e educação"; depois, "gênero e educação" (mesmo assim, naquela época "gênero" era praticamente entendido como "questões da mulher"). À medida que foram sendo concluídas essas primeiras orientações, algumas pessoas finalizavam a pesquisa mas desejavam continuar os estudos. Foi isso que nos fez dar origem ao GEERGE, que é o Grupo de Estudos e Relações de Gênero, em1990.

O GEERGE nasceu como um grupo de estudos, inicialmente pequeno, tendo a mim como professora e as jovens que tinham terminado o mestrado e não queriam deixar de estudar; ou ainda o pessoal que estava cursando

50 SCOTT, Joan. Gênero: Uma categoria útil de análise histórica. Educação \& Realidade, Porto Alegre, v. 15, n.2, jul./dez, 1990 (Uma nova versão revisada do artigo, apoiada no original em inglês, foi publicada, posteriormente, na mesma revista Educação \& Realidade, Porto Alegre, v. 20, n.2, jul/dez. 1995). 
o mestrado. Essas primeiras pessoas vocês conhecem porque continuaram muito ligadas a esta área, até hoje, como a Dagmar Meyer; a Jane Felipe (que veio um pouco depois); a Rosangela Soares ${ }^{51}$. O que a gente fazia fundamentalmente era estudar. Por isso valorizo muito esse período do GEERGE, porque buscávamos o que estava emergindo sobre o campo de estudos de gênero e do feminismo. Procurávamos estar atentas às publicações internacionais. Nos momentos de encontro do GEERGE, desaparecia essa dicotomia entre quem era professora e quem era aluno/a. Havia um clima muito informal e muitas vezes eu me sentia à vontade para dizer: "Não entendi nada do que essa autora ou esse autor está dizendo". Juntos, tentávamos entender, estudando. Foi um período também em que houve muitas greves na UFRGS. Nestas situações, nos encontrávamos com o pessoal do IFCH para ler, por exemplo, Bourdieu: "A dominação Masculina". A Claudia Fonseca, que é uma antropóloga muito conhecida, a Noemi Brito, também da Antropologia, já falecida, outras colegas do IFCH e nós, líamos em francês e íamos traduzindo em conjunto. Aproveitávamos o tempo da greve para também fazer essas atividades.

Mais tarde, algumas pessoas cursaram o doutorado. Logo depois que Dagmar defendeu sua tese, nós duas iniciamos a linha de pesquisa "Educação e Relações de Gênero", que agora se chama "Educação, Sexualidade e Relações de Gênero". Nesse momento, já no ano 2000, o GEERGE começou a mudar suas características, porque estava sob outra coordenação. Já haviam se passado 10 (dez) anos. O GEERGE deixou de ser apenas um grupo de estudos, cresceu e agora reune muita gente; oferece diversas atividades de extensão, cursos e, anualmente, um ciclo de cinema com debates. A gente sente falta daquela fase de estudos, mas está mais difícil de desenvolver estas sessões, porque agora, há muitos novos/as orientandos/as. Se colocarmos todo mundo junto, somos mais de 25 ou 30 pessoas. Portanto, não se consegue mais fazer leitura e discussão minuciosa de texto, acaba parecendo aula. Podemos até fazer, mas já não tem mais aquela marca característica dos primeiros tempos. Entendo que aquela fase foi muito importante para nós do GEERGE - e depois da Linha de Pesquisa - pois nos deu a referência da busca constante de consistência teórica. Essas questões de teoria são extremamente importantes. Nós tivemos um caráter muito mais acadêmico do que militante ou intervencionista. Creio que isso foi bom!

\section{CGT: O GEERGE é um grupo de estudos da Pós-Graduação em Educação da UFRGS?}

Guacira: O GEERGE não tem uma formalização muito grande, mas ele é um grupo de referência, o Grupo de Estudos e Relações de Gênero. Nossa Linha de Pesquisa chama-se "Educação, Sexualidade e Relações de Gênero" e está vinculada ao programa de Pós-Graduação. Há uma estreita ligação

51 Professoras da UFRGS e pesquisadoras do GEERGE. 
entre a LP e o GEERGE e, consequentemente, o grupo é ligado com o Programa de Pós-graduação, mas no GEERGE não temos praticamente qualquer infra-estrutura. Temos uma sala e o que ali existe, em termos de equipamentos e móveis, como mesa, cadeira, computadores, etc., é fruto das pesquisas que o pessoal desenvolve e de onde provêm os recursos. Temos boa acolhida academicamente em termos de espaço, porque o GEERGE é reconhecido na Faculdade de Educação e ele é também muito bem reconhecido fora da Faced, isso sim.

\section{CGT: É interdisciplinar ou é composto só com o pessoal da Educação?}

Guacira: É só o pessoal ligado à Pós-Graduação de Educação. Mas o GEERGE acaba sendo interdisciplinar porque nosso Programa de Pós-Graduação tem esse caráter, integra muitos estudantes que vêm da Enfermagem, da Educação Física, da Psicologia. São pessoas cuja graduação foi cursada em diversas áreas, como vocês também devem ter no GeTec-UTFPR. Isso faz com que as discussões tenham um tom mais interdisciplinar.

\section{CGT: Fale sobre suas pesquisas (muito interessantes por sinal) e como você chegou até elas.}

Guacira: Eu fazia mais pesquisa em História da Educação e História da Educação da Mulher. Fiz algumas em História da Educação de Meninos, que foi um trabalho sobre os colégios Maristas. Mas aos poucos, principalmente com o contato com professores/as e com o pessoal que está na sala de aula, fui percebendo que o que efetivamente lhes incomodava eram questões relacionadas à sexualidade mais do que questões propriamente de gênero. Isso me levou a conduzir meus estudos para a sexualidade. Comecei a estudar um pouco mais sobre sexualidade. Com um caráter mais teórico do que propriamente realizando pesquisas empíricas, acabei entrando nos estudos da teoria "Queer", construindo uma proposta de pesquisa denominada "Educação e Teoria Queer". A tentativa era a de entender como é que um campo de estudo como "Queer", que é tão voltado - como vou dizer? - a ambigüidades, a uma lógica mais pós-moderna, pode se combinar ou se articular com o campo da Educação, que é mais normalizador e disciplinador. Isso tem me feito trabalhar mais no âmbito da reflexão teórica.

Mais recentemente, ando estudando cinema. Gosto muito de cinema. Tenho feito algumas pesquisas relacionadas com "Cinema e Sexualidade"; "Cinema e Teoria Queer". Os seminários que tenho ministrado no Pós, nos últimos anos, têm sido sobre estas temáticas. A intenção é refletir sobre algumas questões da sexualidade, vendo o cinema como uma pedagogia cultural muito significativa no mundo todo (embora eu olhe mais o Brasil nos séculos XX e começo do XXI).

\section{CGT: Com foco no cinema Brasileiro?}

Guacira: Em princípio o foco era este, e minha proposta foi analisar o chamado Road movie, os filmes de estrada. O filme de estrada tem um certo tom das novelas de formação, quer dizer, um herói que sai pelo mundo, o protagonista, e passa por uma série de obstáculos. Alguém que vai se trans- 
formando ao mesmo tempo em que viaja. Tenho procurado fazer disso uma leitura na qual entendo que há as marcas de gênero e sexualidade. Tenho também pensado metaforicamente nas viagens que são feitas nos territórios de gênero e sexualidade. Mas o foco no cinema brasileiro foi alterado. A partir das últimas pesquisas no meu seminário, tenho escrito mais sobre o cinema dominante, isto é, tenho trabalhado com filmes holywoodianos, porque acho que este é um cinema que provocou e provoca muitos efeitos; é um cinema de grande penetração e audiência. A Faculdade de Educação da UFRGS recentemente publicou um número da revista Educação \& Realidade ${ }^{52}$ que traz um dossiê sobre Cinema e Educação, ali publiquei um artigo intitulado "Cinema \& Sexualidade". Já que estou aposentada, minha idéia, atualmente, é trabalhar com algo que me dê prazer, e acho o cinema muito prazeroso. Creio que é impossível ignorar os efeitos pedagógicos do cinema, deixar de considerar que esta é de fato uma instância que exerce pedagogias. Portanto, decidi trabalhar com o filme voltado para o grande público, porque me interessa refletir sobre os efeitos que ele exerce sobre o público. Não se trata de um cinema de elite. Discute-se a sexualidade, por exemplo, nos filmes norte-americanos dos anos 1950, 1970, e indago como se está lidando com a diversidade sexual nos filmes contemporâneos. Como se está lidando com os atravessamentos, a travessia de gênero?

\section{CGT: Comente sobre um filme e a que conclusão você chegou?}

Guacira: Escrevi sobre um filme americano que fez bastante sucesso: Transamérica ${ }^{53}$. É a história de Bree ${ }^{54}$ que está prestes a fazer uma cirurgia para a mudança de sexo, tendo cumprido todas as etapas exigidas para a passagem do masculino para o feminino. Quando ela está para fazer essa cirurgia, descobre que tem um filho resultado da única relação heterossexual que tivera, na época de faculdade. Em vista disso, sua terapeuta diz que ela ainda não pode fazer a cirurgia até resolver a inesperada situação. Ela vai, então, se encontrar com o filho e os dois pegam a estrada, atravessando os Estados Unidos, de Nova York até Los Angeles.

Nessa viagem, o que analiso, são os movimentos no âmbito do gênero, um trânsito de um território masculino ao feminino - o caso de Bree - e também a situação do garoto que está bastante perdido e usa muito o corpo para poder sobreviver. Entre tantas situações, há uma cena que me parece interessante lembrar: às tantas da viagem, na estrada, os dois já estavam se dando bem, até que Bree vai urinar. Ela está sempre toda feminina, toda de cor-de-rosa e, de repente, aparece seu pênis. Essa situação deixa o garoto perturbado. Poderia-se dizer que Bree é queer, no sentido de que tem um corpo estranho, na medida em que tem marcas de feminilidades e a marca sexual masculina. O que eu argumento, contudo, é que, no sentido político de queer, a Bree não é "queer". Porque um sujeito "queer" é alguém que quer viver a posição do entre-lugar, da ambigüidade, mas Bree não quer isso não. Ela deseja muito ser uma mulher no sentido mais tradicional do que ela entende por feminino - que é uma mulher "clássica", dos anos 1950. Ela

52 Revista Educação \& Realidade, Dossiê Cinema e Educação, volume 33, n 1, 2008.

53 Filme do diretor Duncan Tucker lançado em 2005 e distribuído pela Focus Filmes.

54 Personagem principal do filme Transamérica. 
se veste de cor-de-rosa praticamente todo o filme, ela é contida nos movimentos, é toda delicada. Nesta metáfora de viagem que uso, penso que se pode dizer que ela se comporta no território feminino tal como se comporta um imigrante ou um exilado quando está em uma terra estrangeira, ou seja, alguém que geralmente segue muito mais as normas daquela nova terra do que os aqueles que são nativos. Portanto, Bree é uma mulher, enquadrandose o mais possível num estereótipo do feminino, afetadamente feminina. Ela não quer viver a ambiguidade. O que ela quer é ser o que ela chamaria de uma mulher "legítima". É esse tipo de reflexão que faço. Uso o cinema para ajudar a pensar as questões teóricas. Eu não diria que uso o cinema como um pretexto, porque o cinema tem sua própria expressão, ele fala por si, mas digo que o filme ajuda a abordar essas questões e, potencialmente, provoca grandes efeitos já que é algo prazeroso.

Contemporaneamente, o cinema está começando a mostrar a diversidade sexual de forma menos negativa. Tradicionalmente, mostrava os personagens homossexuais como caricatos ou sendo punidos, seja por sofrimentos imensos ou pela morte.

Ainda hoje a televisão e também o cinema representam muitas vezes situações em que alguém que é um homem se passa, momentaneamente, por mulher. Por exemplo, filmes como: "Quanto mais quente melhor"; "Uma babá quase perfeita". Entendo que esse tipo de filmes não chega a propor, propriamente, uma grande transgressão, porque a platéia sabe que aquele personagem está "fazendo de conta que é o que ele não é". Portanto, a platéia se comporta como uma espécie de cúmplice do/a personagem e não sofre; a platéia pode rir junto. Ao passo que num filme como "Transamérica", ou "Traídos pelo Desejo", em que o protagonista vive e sofre a ambigüidade e os desejos proibidos, a platéia é mais desafiada e perturbada. Contemporaneamente, temos visto filmes feitos na ótica dos/as militantes feministas, gays e lésbicas, e que trazem representações positivas de sujeitos/ as homossexuais ou questões ligadas às suas lutas e experiências.

\section{CGT: E tem aquele filme: "O Segredo de Brokeback Mountain"...}

Guacira: Não chegamos a trabalhar com esse filme, mas é muito interessante, já que traz a homossexualidade para um universo super masculino, que é o faroeste.

\section{CGT: A homossexualidade no Brasil tem estado mais presente nas novelas. Em alguns casos com personagens bem caricatos e outros já com perso- nagens bem naturais. Como Você vê esse aumento da representação da homossexualidade nas novelas?}

Guacira: Tenho visto pouca novela recentemente e não tenho estudado a televisão. Mas acompanho o noticiário aqui e ali e tenho visto que estão sendo representados casais homossexuais, tanto mulheres quanto homens. Cheguei a prestar atenção em uma seqüência de novelas onde apareciam casais de lésbicas (numa delas, duas mulheres muito lindas, que acabam morrendo num incêndio); em outra, eram duas garotas em um colégio que 
tinham um relacionamento extremamente controlado pela mãe de uma delas. No final desta novela (Mulheres apaixonadas), apareceu um beijo entre as duas, mas numa peça de teatro em que uma representava o Romeu e a outra, a Julieta. Quer dizer, lançou-se mão de um recurso para ir apresentando aos poucos a afetividade entre pessoas do mesmo sexo. O que eu acho disso? Acho que a televisão não é uma coisa desencarnada de outras instâncias; não se pode entendê-la desconectada do resto. Não creio que a televisão seja aquele demônio que algumas pessoas pintam, mas também não a vejo tão avançada. A Globo, que faz as novelas mais famosas, tem, sim, representado essas situações homossexuais, como também têm apresentado situações de relacionamento inter-raciais aqui e ali. Às vezes aparece alguma situação inter-geracional, que é para dar conta de todo um movimento de visibilidade que esses grupos estão tendo. Mas a Globo faz isso de um jeito bastante pasteurizado. São personagens que se ajustam; são pessoas geralmente de classe média; são relações bastante monogâmicas; geralmente sujeitos brancos. A idéia é sempre fazer de um modo que seja mais aceito pela grande maioria. Creio que é mais ou menos esse o caminho que vem sendo trilhado, mas não tenho mesmo estudado televisão.

\section{CGT: Como estão sendo feitas as pesquisas do GEERGE?}

Guacira: Isso também me interessa contar, porque a gente não tem muito espaço para divulgar. O GEERGE e a Linha de Pesquisa Educação, sexualidade e relações de gênero, da Pós-graduação ficam de algum modo confundidos. São duas entidades mas elas se buscam mutuamente. Temos nesses grupos praticamente os seguintes eixos: a Dagmar Meyer e o Luis Henrique Sacchi dos Santos ${ }^{55}$ trabalham numa temática que é: "Políticas do Corpo e Saúde", com questões relacionadas a políticas públicas. A Dagmar em especial tem analisado a dimensão política (a politização) da maternidade e orientado muitos trabalhos no GEERGE. Os dois trabalham as interrelações de cultura com a saúde e com a educação. Há alguns trabalhos recentes sobre a prevenção da AIDS e questões de gênero e sexualidade. O Fernando Seffner ${ }^{56}$ trabalha com "Masculinidades e Sexualidades". As pesquisas que ele tem feito são sobre as questões da homofobia, da bissexualidade masculina e também sobre a chamada masculinidade hegemônica. A Jane Felipe trabalha com "Infância, Gênero e Sexualidade"; uma temática que é bastante impactante e também com o que ela chama de "pedofilização da sociedade". Observa o quanto a sociedade que condena a pedofilia tem, ao mesmo tempo, uma série de espaços em que promove um olhar erótico para as jovens menores. Ainda, há a discussão sobre a erotização das crianças. A Rosângela Soares ${ }^{57}$ trabalha com "Juventude, gênero e sexualidade". Embora oficialmente ela ainda não esteja incorporada ao programa de Pós-Graduação, ela está bem ligada ao GEERGE. Em termos de eixos são esses.

55 Luis Henrique é professor da Faculdade de Educação da UFRGS.

56 Fernando Seffner é professor da Faculdade de Educação da UFRGS

57 Rosângela Soares é a atual coordenadora do GEERGE 
Muitas de nossas pesquisas lidam com desenho animado e/ou revistas, como, por exemplo revistas de "Boa Forma" ou aquelas dirigidas para o público masculino, como "Sexy". As revistas têm sido alvo de muitos estudos. Também desenhos animados e cinema, visto que várias pessoas fizeram pesquisas nesses segmentos. No momento, o Fernando tem uma orientanda que está trabalhando as masculinidades nas revistas de automóveis. Estes são alguns dos temas. São as tais instancias pedagógicas. Também há alguns estudos sobre internet. Uma orientanda minha fez uma pesquisa sobre os blogs femininos; outro orientando meu está estudando as masculinidades nas torcidas de futebol. Algum tempo atrás uma orientanda minha trabalhou com gastronomia, a partir da revista "Gula". Considero um tema diferente e também interessante de se examinar do ponto de vista da educação.

$\mathrm{Na}$ verdade, como o GEERGE tem quase 20 anos (e com 18 anos adquire-se a maioridade, não é?!) e há muitos estudantes no curso de Pós-Graduação (por ali tem passado muita gente) então, tem-se inventado muitos temas. Um dos estudantes da Dagmar trabalhou com o envelhecimento e gênero. Estou com um orientando de doutorado, atualmente, que está trabalhando com homossexualidade e envelhecimento. Aliás, o título desta Tese de Doutorado é: "Envelhecer nas tramas da Hetero e da Homonormatividade"; quer dizer, há a idéia de que os espaços homossexuais também normatizam. Há os bailes da terceira idade como espaço interessante de estudo e pesquisa. Além disso, como as pessoas vêm de áreas diferentes, há estudantes da Fisioterapia, da Psicologia, etc. e os temas acabam nascendo um pouco a partir de suas próprias áreas, o que vai nos estimulando a pensar coisas diferentes. Tem um campo que está recém se abrindo no GEERGE (embora em outros lugares seja mais estudado) que são as questões de Internet, não só os "blogs". Um dos orientandos do Fernando está trabalhando um site de relacionamento, que é uma forma do exercício da sexualidade muito grande (e que tem a haver inclusive com a situação da AIDS, com sexo seguro... sexo que se faz pela internet). Enfim, são campos onde há muita coisa para estudar e por fazer.

\section{CGT Tem algum tema, além dos mencionados, que Você gostaria de ver estudado?}

Guacira: Não sei. Há muita coisa que me atrai, há muitas coisas importantes, há muitas idéias. Creio que como tem muita gente no GEERGE e na Pós, já fico satisfeita com as coisas que aparecem. Temos publicado bastante e temos um site: <www.geerge.com>, que é uma forma muito boa de podermos contar um pouco dessa história.

\section{CGT: Isso também foi importante para o GT 23 da Anped ${ }^{58}$ ?}

Guacira: Sim, este é um ponto importante a destacar: ter conseguido a efetivação desse GT foi uma realização muito importante. Acredito que o grupo

58 Guacira foi uma das criadoras e primeira coordenadora do Grupo de Trabalho Gênero, Sexualidade e Educação - GT23 da Associação Nacional de Pós-Graduação e Pesquisa em Educação - ANPED. 
ajudou significativamente. A Claudia Ribeiro ${ }^{59}$ foi uma imensa batalhadora pelo GT da ANPED. O GT se constitui numa oportunidade maravilhosa para a gente se encontrar. Temos vários grupos pelo Brasil estudando essas questões que não dialogam entre si. Apesar de não serem todos os que vão à Anped, ainda assim é um espaço importante de diálogo. Não teríamos nos conhecido se não fosse a Anped. Portanto, este espaço inscrito no campo da Educação acaba tendo uma pluralidade teórica, temática, e de ação. Alguns são mais intervencionistas, outros, mais marcadamente grupos de estudos; alguns, de uma matriz teórica, outros, de outra. Isso é muito bom.

\section{CGT: Se Você quiser falar alguma coisa que não foi perguntada, fique a von- tade.}

Guacira: Só tenho que agradecer por esse espaço. Vamos continuar em contato.

[i] Embora Foucault e Barthes tenham proposto a morte do autor, os estudos literários contemporâneos vêm propondo resgatá-lo, ressuscitá-lo por entenderem que autor e obra são interdependentes, complementares, conexos.

59 Professora da Universidade Federal de Lavras, atual coordenadora do GT23 da Anped. 